\title{
Postulational Rhetoric and Presumptive Tautologies: The Genre of the Pedagogical, Negativity, and the Political
}

\author{
Tomasz Szkudlarek ${ }^{1}$ (D) \\ Published online: 16 July 2018 \\ (c) The Author(s) 2018
}

\begin{abstract}
In the paper I analyze two features of the genre of the pedagogical. First is a particular usage of "should" statements (which I call postulational rhetoric) where one can identify an effect of erasing present normative behavior, while that which is postulated is turned into an unattainable ideal, or a value. Second, I analyze "presumptive tautologies" in the discourse of aims of education. I focus on negative dimensions of these two features and, using theoretical insights from Laclau and Rancière, I connect them to the work of negativity in political ontology so that the relation between the pedagogical and the political can thus be re-articulated.
\end{abstract}

Keywords Education $\cdot$ Politics $\cdot$ Rhetoric $\cdot$ Political ontology $\cdot$ Values $\cdot$ Laclau $\cdot$ Rancière

\section{Introduction}

The focus of this paper is on two rhetorical features of the genre of the pedagogical, i.e. on the particular usage of "should" statements (which I call postulational rhetoric, Szkudlarek 2016), and on "presumptive tautologies" in the discourse of aims and conditions of education. In particular, I see how negativity operates in and between these elements of pedagogical discourse. Negativity is understood ontologically here, as a "constitutive matter of education" (Buenfil Burgos 2004), and as linking the genre of the pedagogical with rhetorical means of constructing the political. This relation is explicated in terms of Ernesto Laclau's and Jacques Rancière's theories.

\section{Postulational Rhetoric}

From Rousseau to contemporary critical pedagogy, we find numerous texts where we read what parents, children, or teachers should do. To present an example of the intensity of this persuasive strategy, in Book One of Rousseau's Emile (Rousseau 1921) the word "should"

Tomasz Szkudlarek

pedts@ug.edu.pl

1 Institute of Education, Faculty of Social Sciences, University of Gdańsk, Ul. Bażyńskiego 4, 80-903 Gdańsk, Poland 
appears 69 times, which makes 2.1 times per page on average. However, it is not merely the massive occurrence of such statements that is interesting here. Neither is just the content, or the normative dimension of such statements (the "what" of what one should do). What interests me most is their performative dimension, and, thus, the ontological meaning of postulational rhetoric, and the effects it brings to education and society. Obviously, it positions subjects in particular relations in which one person attempts to execute certain behavior from another. Obviously, it activates normative claims, knowledge about what is proper and improper in given circumstances. However, there are cases when that which is postulated already exists, and this is where the ontological, performative effect is visible most clearly. To give a trivial example, saying "you should keep your room tidy" to a boy who has just cleaned his room not only acts as a statement that positions him and the speaker in asymmetric power relations. Not only does it activate the norm of tidiness and order; it is also a negative statement that invalidates the cleaning done by the boy, making it invisible and insignificant. To give a more complex example, saying that schools should adapt to the demands of knowledge society obliterates the fact that schools always work with knowledge, or that any society is a knowledge society (cf. Foucault's notion of power/knowledge where any relation of power is related to the production and circulation of knowledge; Foucault 1980). Such a statement treats the work already done at the intersections of knowledge and society as invisible and insignificant. In sum, saying that something should exist or be done may erase that which does exist or is being done, and it displaces them from the present to the not-yet existent: postulational rhetoric works as a strategy of invalidation and obliteration of the present. That which is and is invalidated by the statement that it should exist, is turned into that which is not and is desirable: into a value. The very act of saying "you should" may thus be productive of ideal objects of desire, of "tidiness" or a "school adequate to the knowledge society" that are different from those accessible to daily experience. In such cases, postulational rhetoric operates as a "pedagogical vacuum cleaner" that evacuates significance from actual experience and displaces it to the domain of ideal values that must be craved. Craving arrives as a retroactive effect of the very statement of obligation; as desire created by the moment of evacuation.

To explicate the transition from failed norms to desired values, we need a language proposed in Laclau's theory of identity, even though Laclau does not speak of values explicitly. Two issues are recalled here: the first is the role of empty signifiers in the rhetorical construction of identity, and the second is the distinction between normativity and ethics.

Laclau's theory is about how heterogeneous societies attain their political identity, or totality. The "building blocks" of political identities are demands, and as Laclau (2005) argues, it is impossible to move from heterogeneous demands to totality by way of generalization, or sublation of differences as in Hegel's logic. The transition to identity must employ rhetorical figures. The crucial thing here is that social totality has no positive existence: it is a negation of social fragmentation and heterogeneity. This is why it can only be represented by something particular, and that can only be a tropological representation. Laclau identifies it as a synecdoche (pars pro toto) and as catachresis (here, a trope that has the structure of metaphor, but unlike metaphor it is necessary rather than optional in the process of signification). As Laclau says, "totalization requires that one differential element should assume the representation of an impossible whole. (The Solidarność symbols, for instance, did not remain the particular demands of a group of workers in Gdansk, but came to signify a much wider popular camp against an oppressive regime). Thus a certain identity is picked up from the whole field of differences, and made to embody this totalizing function" (Laclau 2005, pp. 80-81). In Laclau's terms, such a universal demand can only operate as empty signifier. At the same time, this moment of elevation of the particular 
"to the dignity of the Thing" (Laclau 2005) is necessary not only for the sake of the political movement gaining its representation in spite of the accomplishment of totality being impossible, but also in order to gain an ethical dimension.

In Laclau, there is as a fundamental difference between normativity (socially construed and recognized norms and regulations), which has positive content, and ethics, which-like totality or identity - is a negative instance. As Laclau says, "the primary ethical experience is the experience of lack: it is constituted by the distance between what is and what ought to be" (Laclau 2004, p. 287). It thus allows for distance to existing norms and opens the space for the change of normative orders. As Carusi (2017) says, ethics may manifest itself in despair rather than hope, bringing disbelief and distance to the normative. Importantly, as a negative instance, ethics cannot be translated directly into a new normative order: it may only be invested in such an order. Quoting Laclau again (2000, p. 81), "there is no logical transition from an unavoidable ethical moment, in which the fullness of society manifests itself as an empty symbol, to any particular normative order. There is an ethical investment in particular normative orders, but no normative order which is, [is] in and for itself, ethical". These excerpts take us closer to understanding values as empty signifiers. Truth, justice, or solidarity are never fully embodied in the normative, because, as empty symbols, they remain beyond such embodiments. What these terms represent is the everelapsing demand for truth, justice and solidarity.

In addressing values and empty signifiers in the context of postulational rhetoric, I am suggesting that ideas, and values in particular, are the product of specific cultural apparatuses that we could call—after Masschelein and Simons (2013a, b)—public pedagogic forms. Postulational rhetoric may be interpreted as one such form implicated in the production of values. Obviously, "should" statements simply recall certain normative orders ("keep your room tidy"); however, with the same gesture they deny that what there is, is "tidiness proper," and thus they evacuate the notion of tidiness to the ideal sphere beyond the given. Such evacuations from the actual to the ideal seem to be occasional and unintentional. Those who say what should be done may not know whether the addressees perceive themselves as following given norms, or not. It is in the first situation that the expression of obligation may operate as an invalidating and universalizing gesture of evacuation that erases the actual appearance of "tidiness" and renders its possible existence desired and valuable. When the norm is not observed, the statement simply acts as a reminder of an existing norm. In other words, education that socializes people to specific normative orders may disrupt these orders simultaneously; by postulating their existence, it implies that they do not exist, and, thus, it contributes to the creation of values. This means that we may thus see education as both implementing given normative orders, which concerns the socialization element of education (Biesta 2010a, b), ${ }^{1}$ and as disruptive of such orders. Both these operations are momentums of the same process.

The understanding of values proposed here is radicalization, and, in a way, a profanation (Agamben 2007) of idealistic axiology. A good starting point to illustrate this transformation is Nicolai Hartmann's notion of values as ideas that "oblige," whose mode of existence is "ought to be," or Seinsollen (Noras 1998). In the understanding proposed here, departing from the Platonic idealism of Hartmann's values, they do not exist (their terms

\footnotetext{
1 Biesta (2010a, b) distinguishes between three aspects of education: socialization, qualification, and subjectification, of which only the latter is specifically educational; i.e. it cannot be provided other than by purely educational means and institutions. Following Rancière, Biesta says that subjectification demands a moment of disruption from the given.
} 
point to emptiness), but they should. They are desired as a negation of that which is never complete, and of that which is invalidated by the pedagogical evacuation in the meaning as proposed here. In this interpretation, values are empty signifiers operating in the domain of the ethical in Laclau's understanding. Their mode of existence is a "positive reverse of the lack," something entirely dependent on negativity, on the non-existence of what they postulate. My thesis is that so understood, values are produced in the pedagogical circulation of terms that lose their connection to people's experience and land in the sphere of ideals that depart from what exists actually.

Postulational rhetoric is not the only pedagogical strategy effective of such disruptive evacuations, and, thus, productive of empty signifiers that operate as values. In another work (Szkudlarek 2016) I point to other such elements of educational practice, like classroom discussion or essay assignments on ever-recurring topics of friendship, responsibility, patriotism, etc., that often conclude with multiplying incommensurable perspectives without providing for a positive and generalized meaning. Instead, their confrontation points to "something more" that remains beyond such perspectives, and thus it reaffirms emptiness of the terms. Such pedagogical outcomes correspond to Laclau's negative understanding of the universal. ${ }^{2}$

As productive of negativity, such displacements build strong connections between education and the political. This is so because the political, according to Laclau, must operate by means of empty signifiers (as I claim, homological with values). While Laclau tends to speak of empty signifiers as arriving in particular contexts of political struggles as if spontaneously, as historically specific representations of chains of particular demands, I maintain that societies do need and have repositories of empty signifiers that are pedagogically produced, culturally retained, and activated when needed in particular struggles (Szkudlarek 2007, 2016). ${ }^{3}$

I am not trying to say that the production of empty signifiers, or terms of values, is a "function" of education in the instrumental sense of the term, as serving something external to it. Whatever is pedagogically constructed as politically significant turns back to the educational as its constitutive element. This can be illustrated by the second of the concepts that I announced in the beginning of this paper-presumptive tautology.

\section{Presumptive Tautology}

The term "presumptive tautology" was proposed by Bingham (2010), who analyzed Jacques Rancière's radical assumption of the equity of all intelligences (Rancière 1991) as his contribution to the debate on how philosophers of education "do what they do". The way I use this term speaks both to the way educational theories are built, and to the conditions of educational practice being effective beyond that which is determined externally.

The Rancierèan way of dealing with tautology has a history that must be recalled to make it operational here. We should recall that Rancière criticized Bourdieu's theory of the cultural reproduction of inequalities as being tautological. Bourdieu describes circular transformations of the forms of capital. Cultural capital, crystallized as habitus, derives

\footnotetext{
2 The negative understanding of universality has a theological connotation in Laclau (2014).

3 Laclau (2005) asserts the discursive production of emptiness. However, he does not speak on empty signifiers being produced by specific cultural/pedagogical practices prior to their employment in identity struggles, or "stored" in cultural repositories before being employed in such struggles.
} 
from economic and social capital, and it becomes the main criterion of exclusion in schools. These exclusions determine the impossibility of students from lower social strata to change their economic status. This means that economic capital determines cultural capital that determines economic capital. As Rancière (2007) notes, Bourdieu is aware that this observation does not disclose anything unknown previously, therefore the core of his theory lies elsewhere, in identifying the logic of making this mechanism invisible to those who are excluded. Schools segregate their students while apparently preventing segregation through programs that are focused on providing equal opportunities for all (Bourdieu and Passeron 1990). As Kristin Ross (1991, xi) captures this logic, working class students "are excluded because they don't know why they are excluded; and they don't know why they are excluded because they are excluded".

Pelletier (2009, p. 141) notes that Rancière "does not target the methodological validity of Bourdieu's research, its 'veracity' as it were, but rather its performative effect". In other words, what is at stake is the politics of Bourdieu's theory, that which it "does" to society, to sociology, and to the subjects it is investigating in particular. The problem is that Bourdieu's sociology fixes the distinctions that it claims to challenge; the way it is structured needs, on the part of the working class, their misrecognition of factors that exclude them, because recognition is reserved for the sociologist himself. As Pelletier notes, Rancière's critique points to a problem similar to one identified by Butler in her "Gender Trouble." On the one hand, fixed identity creates the conditions of theorizing a group and to mobilizing them as not only theoretical subjects, but also as political ones. However, on the other hand, it immobilizes them in their original position and thus ruins claims to emancipation. Rancière (2007) is very persistent in pointing to this fixity of Bourdieu's subjects. It results in eliminating ambivalence and mimicry, the use of borrowed languages, or the copying of given cultural practices in Bourdieu's description of the dominated classes. There is no room for social mixing, for encounters between individuals from diverse social strata, or for places of such encounters. In short, there is no room for either collective or individual emancipation, because the fundamental assumption of inequality, crystallized in the notion of habitus as culturally produced and reproduced "nature" of social classes, reproduces itself throughout the whole theory. As Rancière (1991) says, one cannot achieve equity once inequality has been established as the point of departure. The tautology in Bourdieu is a mark of the theory's political impotence (an observation also made by Giroux 1983), of its being trapped in its own negative presumptions. Inequality, once assumed, will only change shapes and positions: the desired equity will never come.

Apparently, this vision has something in common with Laclau's ontology where a socially desirable totality ("a fully reconciled society") is unattainable. However, Bourdieu does not propose a way out of this impossibility, while Laclau does through his departure from structural determination to rhetorical investment. In a way, Bourdieu, Laclau, and Rancière share a similar assumption as to the impossibility of establishing once and for all a "good society" that meets hopes for popular emancipation. In Bourdieu this is impossible because the privileged class defends its position by making the rules of exclusion invisible to the excluded. In Laclau, societies will always be heterogeneous and driven by antagonism. In Rancière, collective emancipation is impossible, and crystallizations of society (which he calls the police) are successfully maintained by aesthetic rules of perceptibility. However, all three authors react to these impossibilities differently. Bourdieu mourns the 1968 aura of revolutionary hope, while educational policies inspired by his diagnoses result in tactics of compensation that are eventually accused of promoting mediocrity. Laclau turns to populist movements and transposes their strategies into a social ontology; societies cannot be changed owing to historical necessity (as in Hegel) or structural determination 
(as in Marx), but by articulating their diverse demands and rhetorically represent them as their identity. Rancière asserts that any police order can be ruptured by disagreements that challenge its rules of (in)visibility, and it is in such momentary ruptures that the politicalwith its radical understanding of equity-is possible.

Accusing Bourdieu's theory of being tautological, Rancière seems to say, paradoxically, that tautology is inevitable, but one has to propose the right tautology. One can capture this approach in performative terms by saying that the wrong, or a negative tautology (like that of inequality) is wrong, but a good, or positive tautology-like that of equity, even if it is counterfactual—can be good. Tautology means here that assumptions have the power of reappearing, of becoming what they already are, of asserting themselves in subsequent iterations; therefore in both thinking and doing one must take what one desires as the point of departure rather than assuming it as a value-a remote quality that does not exist but should. It is in this context that Rancière reads the histories of workers' leaders (2012) or of Joseph Jacotot's pedagogical experience (1991). In his terms, if we want social equality, we must make the (counterfactual) assumption that we are equal, and we must act accordingly. It is our acting accordingly to the assumption that verifies it, that makes it true.

\section{Ontology and the Genre of the Pedagogical}

The general assumption that I have been trying to "verify" for some time, and this paper is one of the steps on this path, is that education, with its particular and irreplaceable pedagogic forms, does much more than make adults of children, active citizens of passive subjects, qualified workers of ignorants, or autonomous subjects from dependent beings. It is ontological machinery, a slow and persistent mill that produces cultural repositories, subjective capacities, as well as social and political orders, which, at the same time, are all subversive to the very same orders. In other words, education is never fully functional to given social orders; rather, it is an ontological condition of any social order. The case of the two pedagogic forms discussed here, postulational rhetoric and presumptive tautology, seems to be a good example of the excessive, over-functional work of education. I will try to clarify now.

The disruptive language of Rancière's political philosophy, including its pedagogical excursions, inspired a significant group of authors (e.g. Biesta 2010a, b; Bingham et al. 2010; Hodgson et al. 2018; Lewis 2014; Masschelein and Simons 2013a) to radically refresh the language of educational theory. Being close to the ontological understanding of education as proposed here, they construe a theory that is politically progressive by means of re-vitalizing traditional repertoires of pedagogical forms. However, one of its founding elements, the presumptive tautology of assuming that which is desired and then making it true, seems to be a fairly persistent, if not constant, element of educational philosophy and theory; in other words, it is not limited to the Rancierèan approach. By no means is this statement intended to blunt the radical edge of this theoretical movement, for it is only after the figure of presumptive tautology has been identified can one start tracing its genealogy, its transformations, and diverse discursive operations. So, one can find this figure in Herbart (1835). The assumption of the educability (Bildsamkeit) of the child, made before the establishment of public schooling, was no less radical and counterfactual than the assumption of the equity of all intelligences adopted by Jacotot. One finds it in Rousseau, whose idea that we are all good by nature is perhaps the most rebellious of those listed here. In Christian Europe, it was the act of christening, and not of birth, that was believed to position individuals on the path to goodness. Interestingly, one finds the 
same figure-enunciated literally - as early as in Plato. In Meno, Socrates explains that the possibility of everybody coming to adequate knowledge is grounded in assuming that all possess all knowledge by virtue of metempsychosis; that it is inherited from experiences gained in previous lives. Moreover, Socrates is fully aware that this may be a false assumption, but nevertheless it must be made for performative reasons, for the sake of the possibility of inquiry.

Some things I have said of which I am not altogether confident. But that we shall be better and braver and less helpless if we think that we ought to enquire, than we should have been if we indulged in the idle fancy that there was no knowing and no use in seeking to know what we do not know; - that is a theme upon which I am ready to fight, in word and deed, to the utmost of my power

Plato (2008, XXI B-C)

To put it in Rancière's language, Socrates makes a radical assumption that everybody can know, and he verifies this assumption by arranging conversations through which his interlocutors reveal knowledge in themselves. In spite of the strongly negative attitude that Rancière (2007) assumes against Plato, mostly due to his division of thinking and doing among social strata, this seems to be quite a Rancierèan approach.

Can we assume that presumptive tautology and postulational rhetoric are typical of the genre of pedagogical discourse? I think that, cautiously, we can. The cases investigated here make a preliminary pretext for this assumption, and one has to expand the scope of similar analyses to make a stronger case. Being based on pretext, however, this claim can be given more substance when we try to find possible connections between the two instances of negativity. Do they work together? Is there a logic behind their possible relations, a pathway of transformations and circulations of negativity, from the rhetorical evacuation of values from the actual to the ideal - to counterfactual assumptions that need performative verification in order to become tautological? And is there a place somewhere in between for hopeless, "negative" tautologies like those criticized by Rancière in Bourdieu's theory? I think this is indeed the case. In short, what is created by postulational rhetorici.e. values as that which does not exist but ought to-return to the domain of practice as the aims of education. Let me gather some of the small-scale conclusions made before and see in more detail what landscape they form together.

We have seen that the extensive use of "should" statements in education can produce, in cases when that which is postulated actually exists, the peculiar effect of evacuating positive qualities from given practices and displacing them to the sphere of ideas, changing them into values that do not have actual existence, whose mode of being is obligation. In a more radical tone, they do not exist, but they should. As such ideals are immune to negligence or misdoing, they-in a Platonic mood-become "more real", by virtue of their stability, than always vulnerable and contingent normativity. Normative behavior is thus transformed into a quasiHegelian appearance, a failed incarnation of values. As I said before, this idealistic account has its contemporary and profane reflection in Laclau's theory of identity, where ethics, as pure negativity, makes contingent normativity questionable and thus open to transformation. In short, I have described the performative effect of postulational rhetoric as productive of empty signifiers, and I have identified these signifiers with values.

This negative effect of the evacuation of given qualities from the normative and actual to the ideal, is fundamentally important for the construction of collective identities. Recalling Laclau again, societies can attain their identities through signifiers that, by virtue of their emptiness, have the capacity of integrating incommensurable demands and linking 
them to the impossible totality of the social. Laclau says that this is a process in which such signifiers emerge by particular demands being invested with the meaning of totality. My observation is that such investment must engage terms of values, words like "justice," "truth," "freedom," etc., which, in turn, implies—and this idea is missing in Laclau (Szkudlarek 2016) — that there are commonly accessible cultural repositories of such terms that are, and can only be, pedagogical constructions. Not only do their meaning need being created, which we may assign to the work of culture in general, of which education is but an element, but they need to be made empty (evacuated from particular experience), publicly accessible, recognizable, and desired as values as well. Without such qualities they could never work as signs of desirable and impossible fullness, and the work of political identity would never be possible. Terms of values - empty signifiers employable in political constructions of society — can only be construed pedagogically.

As I have mentioned, the pedagogical production of values/empty signifiers should not be treated as a cultural or political function of education. This is not a matter of external functionality. Whatever is created pedagogically as cultural or political, immediately feeds back to the pedagogical. Empty signifiers as/and values, which, as I argue, are the product of specific pedagogic forms, are at the same time employed as aims or as conditions of possibility of education.

As the discussion on Rancière's critique of Bourdieu shows, we should probably treat the two modes of tautology (the "negative" one identified in Bourdieu and the "positive" one developed after Jacotot) differently. It seems that the logic of value as that which is not but obliges gives preference to the negative mode of being tautological. In this axiological framework, education starts with the lack of what should be, with all the consequences identified in Rancière's critique of Bourdieu. However, in spite of its inefficiency in bringing equity, freedom, or justice down from the high and now from the eternally delayed future, this pedagogy has a productive effect. Its tautology reasserts values, strengthens their elevated status, and refreshes the desire and political demands for their becoming. This is not a purely Platonic idealism; I am not attempting to say that education is meant to "serve" values in their lofty, sacred, and exclusive domain. What I mean as positive in this pedagogical failure is that value-driven education prepares the ground for the rise of political radicalism where the promised land of justice, truth, or freedom will be claimed by the people. It would be very difficult to imagine a revolutionary re-volution, a turn to ethics from the lack of justice, if people who experience injustice did not have at their disposal a vague notion of justice, of that which the "in" prefix signifies as absent. This is why I insist on the work of terms of values, empty as they are, in populist mobilizations so brilliantly analyzed by Laclau. To conclude this section, every failure of embodiment, of bringing values down now from their Platonic kingdom, reasserts their status as values, as that which is not and is important, and thus it feeds the desire of embodiment. This argument may be read as an account on the production and reproduction of utopian demands, of the energy that feeds populist revolutions, and as a radical, performative reading of Platonic idealism that appears to me to be just a momentum in the circulation of negativity.

And there is the second line of tautology, proposed by Rancière and developed by his pedagogical followers, that differs from the axiological logic of education guided by absence, by that which is not. It works, in a way, backwards-not from the normative lack to ideal values and failed attempts at their embodiment, but from that which is desired towards the sphere of presence, to positivity rather than negativity. It might be abbreviated as follows: if you want equity, ignore its absence and make it your own. Act as if it was already there, and ignore its being a "value", something to dream about that is always missing. Once again, rather than starting from that which is not and should become, assume that it is here right now and act accordingly. Presumptive tautology 
will do its job and you will be equal, because you are. This is the anarchistic logic of ignoring impossibility, a punk theory (Szkudlarek 2017) of acting here and now with no regard for future emancipations, since those never come. Negativity takes a form of ignorance here. Rancière (1991) says that this is a logic of individual emancipation, that it is not possible to stage it "for" somebody, in the form of pedagogy or public curriculum. He denies that Joseph Jacotot had a pedagogy, but I find this denial problematic. Perhaps it simply serves Rancière's need of being consistent in his research, of reading Jacotot exactly as he read the files of activist workers who spent their time writing poems or journal papers. It was that research (Rancière 2012) that pointed to complex histories of individual emancipation, of subjectification against the identification of being "a worker." Hence his insistence on social mixing, on hybrid forms of activism, on sharing space and splitting time between activities that do and do not belong to what is predicted in police regimes of divisions of the sensible. Still, Jacotot was a teacher, and reading Rancière's (1991) account of his pedagogical experience, one cannot not note that it $i s$ a description of pedagogy. And let me recall the observation on the presence of presumptive tautologies in other pedagogical conceptions. Apparently, the logic of emancipation described by Rancière as individual, disruptive, and impossible to organize "for" somebody must have its institutional sister, and an old one. It needs to be investigated what this institutional variety of ignoring the absence, of acting against turning human freedom, justice, or equity into remote ideas-even by Plato himselfbrings to individual subjects, to the public, and to social ontology in general.

It seems, therefore, that education is simultaneously part and productive of at least two modalities of the political. The idealistic one that, in spite of (or owing to?) its conservative, Platonic connotations, is an accomplice to populist revolutions, and the anarchic one that ignores the logic of impossibility and of eternal values that demand waiting for embodiment. Perhaps, as Laclau says, in spite of being politically necessary, society is truly impossible in ontological terms. And perhaps some people just do not know about this or are insolent enough to ignore this knowledge. This is how they can be free to act now. And, besides all this, education can still be seen as functional to job markets, to given political regimes and normative orders, to specific cultural memories, or to parental fantasies of a better life for their children.

To conclude, I have argued, first, that the genre of the pedagogical involves a circulation of negativity between postulational rhetoric, as productive of values, and presumptive tautologies where these values are addressed as aims of education-in two specific, negative (conservative) and positive (anarchistic) logics. My comment on the ongoing debate on the Rancierèan approach to equity in contemporary philosophy of education is that what we usually read from Rancière, i.e. his insistence on making positive assumptions and verifying them in practice, may be a constitutive feature of the pedagogical, dating back not only to the roots of the modern theory of education (like Rousseau and Herbart), but even to Plato as well. Second, as productive of empty signifiers (terms of values) and as operating beyond that which has been determined externally (cf. counterfactual assumptions as the condition of education), the discourse of education can be read as providing rhetorical instruments indispensable in the construction of the political. What I claim is that educational discourse can be analyzed beyond the question of its being functional or reactive to current politics, or being separate from any politics. It can be seen as a condition of the political as such, in other words - as a condition of possibility of any politics at all.

Funding Funding was provided by Narodowe Centrum Nauki, Poland (Grant No. NCN UMO-2014/15/B/ HS6/03580). 
Open Access This article is distributed under the terms of the Creative Commons Attribution 4.0 International License (http://creativecommons.org/licenses/by/4.0/), which permits unrestricted use, distribution, and reproduction in any medium, provided you give appropriate credit to the original author(s) and the source, provide a link to the Creative Commons license, and indicate if changes were made.

\section{References}

Agamben, G. 2007. Profanations. New York, NY: Zone Books.

Biesta, G. 2010a. Good Education in the Time of Measurement. Ethics, Politics, Democracy. London: Routledge.

Biesta, G. 2010b. A New Logic of Emancipation: The Methodology of Jacques Rancière. Educational Theory 60(1): 39-59.

Bingham, Ch. 2010. Under the Name of Method: On Jacques Rancière's Presumptive Tatutology. In What do Philosophers of Education do? (And How Do They Do It?), ed. C. Ruitenberg, 87-102. Malden, MA, Oxford: Wiley-Blackwell.

Bingham, C., G. Biesta, and J. Rancière. 2010. Jacques Ranciere: Education, Truth, Emancipation. London; New York: Bloomsbury Academic.

Bourdieu, P., and J.-C. Passeron. 1990. Reproduction In Education, Society and Culture. London, Thousand Oaks, New Delhi: Sage.

Buenfil Burgos, R. 2004. Negativity: A Disturbing Constitutive Matter in Education. Journal of Philosophy of Education 38(3): 429-440.

Carusi, F.T. 2017. Why Bother Teaching? Despairing the Ethical Through Teaching that Does Not Follow. Studies in Philosophy and Education 36(6): 633-645.

Foucault, M. 1980. Power/Knowledge: Selected Interviews and Other Writings, 1972-1977. (C. Gordon, Red.). 1st American ed. New York, NY: Vintage.

Giroux, H. 1983. Theories of Reproduction and Resistance in the New Sociology of Education: A Critical Analysis. Harvard Educational Review 53(3): 257-293.

Herbart, J.F. 1835. Umriss pädagogischer vorlesungen. Göttingen: Dieterich.

Hodgson, N., J. Vlieghe, and P. Zamojski. 2018. Manifesto for a Post-critical Pedagogy. Santa Barbara, CA: Punctum Books.

Laclau, E. 2000. Identity and Hegemony: The Role of Universality in the Constitution of Political Logics. In Contingency, Hegemony, Solidarity. Contemporary Dialogues on the Left, ed. J. Butler, E. Laclau, and S. Žižek, 44-89. London: Verso.

Laclau, E. 2004. Glimpsing the Future. In Laclau: A Critical Reader, ed. S. Critchley and O. Marchart, 279328. London: Routledge.

Laclau, E. 2005. On Populist Reason. London; New York: Verso.

Laclau, E. 2014. On the Names of God. The Rhetorical Foundations of Society, 37-51. London; New York: Verso.

Lewis, T.E. 2014. The Aesthetics of Education: Theatre, Curiosity, and Politics in the Work of Jacques Ranciere and Paulo Freire. New York, NY: Bloomsbury Academic.

Masschelein, J., and M. Simons. 2013a. The Politics of the University: Movements of (de-)identification and the Invention of Public Pedagogic Forms. In Education and the Political. New Theoretical Articulations, ed. T. Szkudlarek, 107-120. Rotterdam, Boston and Taipei: Sense Publishers.

Masschelein, J., and M. Simons. 2013b. In Defence of the School. A public Issue. Leuven: Education, Culture and Society.

Noras, A. 1998. Nicolaia Hartmanna koncepcja wolności woli. Katowice: Wydawnictwo Uniwersytetu Śląskiego.

Pelletier, C. 2009. Emancipation, Equality and Education: Rancière's Critique of Bourdieu and the Question of Performativity. Discourse: Studies in the Cultural Politics of Education 30(2): 137-150.

Plato. 2008. Meno. Trans. Benjamin Jowett. The Project Gutenberg Ebook.

Rancière, J. 1991. The Ignorant Schoolmaster. Stanford: Stanford University Press.

Rancière, J. 2007. Philosopher and his Poor. Durham: Duke University Press.

Rancière, J. 2012. Proletarian Nights. The Workers' Dream in Nineteenth-Century France. London and New York: Verso.

Ross, K. 1991. Translator's Introduction. In The Ignorant Schoolmaster, ed. J. Rancière. Stanford: Stanford University Press.

Rousseau, J.J. 1921. Emile, or Education. Library of Liberty Project. http://lf-oll.s3.amazonaws.com/titles/2256/ Rousseau_1499_EBk_v6.0.pdf. Accessed December 4, 2017. 
Szkudlarek, T. 2007. Empty Signifiers, Education and Politics. Studies in Philosophy and Education 26(3): 237-252. https://doi.org/10.1007/s11217-007-9033-7.

Szkudlarek, T. 2016. On the Politics of Educational Theory: Rhetoric, Theoretical Ambiguity, and the Construction of Society. London: Taylor and Francis.

Szkudlarek, T. 2017. Punk Theory: The Future of Thinking in the Time of No Future. Research in Education 97(1): 49-55. 